\title{
EDITORIAL
}

\section{Issues of identity}

\author{
Sheila Hollins
}

Do we have more in common with each other as psychiatrists, regardless of specialism, or do we identify more closely with other mental health professionals working with our particular client group? Sometimes it seems, with our ever-increasing specialisation, that psychiatrists are operating in separate worlds and have nothing in common with each other. The College has just established new faculties in liaison psychiatry and in social and rehabilitation psychiatry, and new sections and special interest groups. But do any of us feel we have a good grasp of new developments in each other's fields? I believe that our specialist roles and skills need to be built on the sound base of a shared identity.

\section{Individual professional identity}

The setting in which we practice, the age and clinical needs of our patients and the theoretical model we espouse may differ, but I suggest we have more in common as psychiatrists than we sometimes think.

For example, my professional identity is first as a doctor then as a psychiatrist, although my clinical work is in the specialty of learning disability. Some years ago I was 'accused' by a colleague of not being sufficiently identifiable as a psychiatrist, rather as someone who knew about a wide range of issues and concerns in the learning disability field. Reflecting on this I realised that much of my expertise came from integrating and developing further the knowledge and skills I had gained from previous work as a general practitioner, as a child psychiatrist and as a psychotherapist. Many colleagues also have family experience of learning disability or mental health problems, as I do myself. We all bring our other lives and experiences into our work as psychiatrists, and I believe that these enrich our relationships with our patients. My background led me to develop an interdisciplinary and community-based approach to psychiatry, although my clinical work now is largely in a specialist psychotherapy service for adults with learning disability who have suffered trauma. Over the years, I have worked closely with colleagues in forensic psychiatry and with adult and old age specialists regarding issues that affect my patient group. The truth is that my patients suffer the full range of mental and physical health and personality problems seen in the rest of the population although probably more frequently. This may be helpful in understanding why I am interested in exploring what we have in common as psychiatrists.

\section{What do psychiatrists do best?}

So what are the distinctive contributions to patient care that we make as psychiatrists? The biopsychosocial understanding that a psychiatrist brings to clinical work is central. This cannot be subdivided into each of its three component parts. The synthesis of these three separate disciplines in psychiatric training achieves an understanding which is so much more than their simple summation might suggest. For example, within multidisciplinary health care teams we will probably be the only expert diagnosticians and the only discipline able to consider the possible physical causes of our patients' symptoms, and we may need to remind colleagues about the importance of a comprehensive differential diagnosis.

\section{Sharing responsibility}

Then there is the question about clinical responsibility for patients. Is this uniquely our role or are there circumstances in which it can be shared? How effective are our colleagues in other disciplines when some of these responsibilities are delegated or distributed to them, or does such sharing lead to a loss of authority or effectiveness? Research suggests that consultant psychiatrists who have adopted

Sheila Hollins is Professor of the Psychiatry of Learning Disability and Head of the Department of Mental Health at St George's Hospital Medical School (Cranmer Terrace, London SW17 0RE, UK. E-mail: shollins@sghms.ac.uk). She is Vice-President of the Royal College of Psychiatrists. Her research interests include the effects of abuse and bereavement on mental health and the effectiveness of psychological interventions. 
newer ways of working, such as moving from more traditional psychiatrist-centred services to more consultative partnerships, are less stressed than psychiatrists who practise more conventionally. They also work shorter hours (Pajak et al, 2003). Owing to acute shortages of psychiatrists, many consultants have been working exceptionally hard, even to the point of burnout, still carrying clinical responsibility for all patients referred to 'their' team. But there could be many opportunities for sharing responsibility. For example, patients held under the Mental Health Act must, by law, be assigned a responsible medical officer (RMO), but do all 'informal' patients have to be in the care of RMOs (Kennedy \& Griffiths, 2002)?

The College has been working with other disciplines to consider new ways of working in the area of clinical responsibility. It is suggested that we could share more of our skills with other disciplines, and further develop our own high-level consultancy and supervisory skills to support them. In consequence, we would need to carry direct clinical responsibility for only the more complex patients. We would need to offer leadership in implementing practice guidelines in such a way as to accommodate, rather than ignore, the unique needs of some patients who do not fit into standard clinical pathways. Some may find these ideas rather challenging and lack confidence in being able to defend the distinctive role of the psychiatrist, if some of the things we have been comfortable doing are now to be taken on by other members of the multidisciplinary team.

\section{Implications for CPD}

There are some obvious CPD needs that begin to emerge from these lines of thought. These include leadership and supervisory skills, and they will be needed by all of us, not just by one specialty or another. Also, it is important to support trainees to begin to address them before they become consultants. And, of course, Advances in Psychiatric Treatment strives to provide a comprehensive range of articles updating all of us, and not just in our primary field of interest.

\section{References}

Kennedy, P. \& Griffiths, H. (2002) What does 'responsible medical officer' mean in a modern mental health service? Psychiatric Bulletin, 26, 205-208.

Pajak, S., Mears, A., Kendall, T., et al (2003) Workload and Working Patterns in Consultant Psychiatrists. An Investigation into Occupational Pressure and Burdens. London: College Research Unit, Royal College of Psychiatrists.
NOTICE TO SUBSCRIBERS

\section{Don't forget to renew your subscription}

\author{
to
}

Advances in Psychiatric Treatment for 2005

2005 subscription prices can be found via www.rcpsych.ac.uk/publications/apt_info.htm

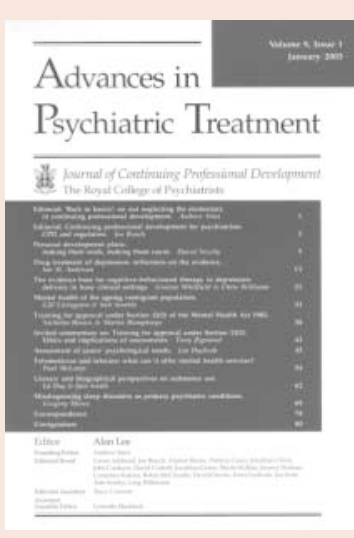

To renew your subscription (or for related queries), please contact:

Subscriptions Department, Maney Publishing, Hudson Road, Leeds LS9 7DL, UK.

Tel: + 44 (0)113 249 7481. Fax: + 44 (0)113 248 6983. E-mail: subscriptions@ maney.co.uk 